\title{
Biology of Aging
}

National Cancer Institute

\section{Source}

National Cancer Institute. Biology of Aging. NCI Thesaurus. Code C19685.

The study of the biological reasons and mechanisms of human aging. 